\title{
METODE MULTI ATTRIBUTE DECISION MAKING DENGAN MODEL SIMPLE ADDITIVE WEIGHTING SEBAGAI PENDUKUNG KEPUTUSAN PEMBERIAN PINJAMAN
}

\author{
Alhibarsyah* \\ STMIK Tunas Bangsa, Bandar Lampung \\ Jl. Z.A Pagar Alam No. 17A Rajabasa Bandar Lampung \\ alhibarsyah.aal@gmail.com
}

\begin{abstract}
Decision support systems are used to solve a problem that is commonly done by users and industry, in this case one of the application of a decision support system in providing loans to cooperative members. Judging from the form of business, cooperatives are one of the community financial institutions that are formed and are not only business-oriented, but social factors are very strongly applied. Because the cooperative was formed to help and prosper its members, such as saving and borrowing (credit) from its members. In this study, decision making is used to help support the selection of loan applications for members. There are several types of decision models that are integrated in a Decision Support System such as statistical models, optimization models, heuristic models and multi-criteria / attribute models. The Simple Additive Weighting (SAW) method is used with the basic concept of finding the weighted sum of the performance ratings on each criterion. According to the MADM model which is used as decision support who can select criteria in determining the eligibility of members in receiving loans (credit). The system provides a solution in determining loan recommendations to prospective borrowers in cooperatives. The system is only able to represent 10 sample members as a reference in calculating credit lending.
\end{abstract}

Keywords: Decision; Cooperative; MADM; Loan; SAW

\section{Pendahuluan}

Pemberian pinjaman (kredit) kepada anggota koperasi adalah salah satu upaya koperasi untuk memberikan bantuan sebagai wujud cita-cita koperasi, mensejahtrerakan anggotanya. Dalam pemberian kredit kepada anggota diperlukan analisa keperluan pinjaman tersebut. Analisa tersebut diperlukan sebagai syarat didalam menentukan layak atau. tidaknya anggota untuk menerima pinjaman. Oleh karena itu, selain sistem informasi yang diperlukan untuk pengelolaan data koperasi, diperlukan juga suatu sistem pengambilan keputusan untuk mendukung penyeleksian pengajuan pinjaman anggotanya. Diperlukan suatu model pengambilan keputusan sebagai sarana yang memberikan dukungan bagi pengambilan keputusan oleh pengambil keputusan. Terdapat beberapa jenis model keputusan yang terintegrasi dalam suatu Sistem Pendukung Keputusan seperti model statistik, model optimasi, model heuristik dan model multi kriteria/atribut.
Metode Simple Additive Weighting (SAW) yang digunakan dengan konsep dasar mencari penjumlahan terbobot dari rating kinerja pada setiap kriteria. sesuai dengan model MADM yang digunakan sebagai pendukung keputusan yang dapat menyeleksi kriteria-kriteria dalam menentukan kelayakan anggota dalam menerima pinjaman (kredit). MADM dipilih sebagai model keputusan karena memiliki karakteristik yang dimiliki banyak kriteria/atribut dan alternatif, dimana alternative-alternatif tersebut diberikan secara eksplisit. MADM memiliki kemampuan untuk melakukan penilaian secara lebih tepat karena didasarkan pada nilai kriteria dan bobot prefensi yang sudah ditentukan, kemudian dilanjutkan dengan proses perangkingan yang akan menyeleksi alternative terbaik dari sejumlah alternatif yang ada.

\section{Bahan Dan Metode}

A. Konsep Sistem Penunjang Keputusan Konsep Sistem Pendukung Keputusan (SPK) / Decision Support Sistem (DSS) pertama kali 
diungkapkan pada awal tahun 1970-an oleh Michael S. Scott Morton dengan istilah Management Decision Sistem. Sistem tersebut adalah suatu sistem yang berbasis komputer yang ditujukan untuk membantu pengambil keputusan dengan memanfaatkan data dan model tertentu untuk memecahkan berbagai persoalan yang tidak terstruktur. Istilah SPK mengacu pada suatu sistem yang memanfaatkan dukungan komputer dalam proses pengambilan keputusan.

\section{B. Pengertian Kredit}

Secara umum kredit diartikan sebagai suatu kegiatan peminjaman sejumlah modal oleh pemilik modal kepada pengguna modal dalam hal ini terdapat unsur kepercayaan berupa keyakinan diberikan kepada penerima kredit bahwa pinjaman yang disepakati bersama akan terlaksana dengan baik. Selain unsur kepercayaan, ada unsur waktu yang merupakan suatu periodik yang memisahkan saat pemberian kredit dan penerimaan kredit.

Dari beberapa pengertian diatas maka dapat disimpulkan bahwa kredit merupakan ikatan perjanjian yang disertai dengan dokumen-dokumen legal antara pihak pemberi kredit sebagai pihak kreditur dan pihak lain sebgai pihak peminjam atau debitur yang menerima suatu prestasi yang berupa uang atau jasa-jasa pengembalianya dilakukan pada waktu tertentu yang telah ditetapkan pada masa yang datang dengan memperhitungkan tingkat resiko tertentu dan balas jasa bunga sebagai kontra prestasi yang merupakan pendapat bagi pihak debitur.

Intisari dari kredit adalah unsur kepercayaan, dilihat dari pihak kreditur, kegiatan kredit adalah untung mengambil keuntungan dari modal dengan mengambil keuntungan dari modal dengan mengambil kontraprestasi, sedangkan dipandang dari segi debitur, kegiatan kredit adalah adanya bantuan dari kreditur untuk menutup kebutuhan berupa prestasi.

(M. Fuad Cristin H. dan sugiarto Paulus, Y.E.F, 2010) mengemukakan bahwa kredit adalah hak untuk menerima pembayaran atau kewajiban untuk melakukan pembayaran pada waktu diminta, atau pada waktu yang akan dating,karena penyerahan barangbarang sekarang.

\section{Konsep Dasar Multi attribute Decision Making (MADM) \\ Pada dasarnya proses Multi Attribute} Decision Making dilakukan melalui tiga tahap, yaitu penyusunan komponen-komponen situasi, analisis, dan sintetis informasi (Rudolphi,2000). Sebagian besar pendekatan Multi Attribute Decision Making dilakukan melalui dua langkah, yaitu pertama melakukan agregasi terhadap keputusan-keputusan yang tanggap terhadap semua tujuan pada setiap alternatif dan kedua melakukan perankingan alternatif-alternatif keputusan tersebut berdasarkan hasil agregasi keputusan. Dengan demikian, bisa dikatakan bahwa masalah multi attribute decisionmaking adalah mengevaluasi $\mathrm{m}$ alternatif $\mathrm{Ai}(\mathrm{i}=1,2, \ldots, \mathrm{m})$ terhadap sekumpulan atribut atau kriteria $\mathrm{Cj}$ $(\mathrm{j}=1,2, \ldots, \mathrm{n})$, dimana setiap atribut saling tidak tergantung satu dengan yang lainnya. Matriks keputusan setiap alternatif terhadap setiap atribut $\mathrm{X}$ diberikan sebagai :

$X=\left\{\begin{array}{c}x 11 \quad x 12 \ldots . . x 1 n \\ x 11 \quad x 12 \ldots . x 2 n \\ \ldots \ldots \ldots \ldots . . . \\ x m 1 \quad x m 2 \ldots . x m n\end{array}\right\}$

Dimana xij merupakan rating kinerja alternatif ke-i terhadap atribut ke-j. Nilai bobot yang menunjukkan tingkat kepentingan relatif setiap atribut, diberikan sebagai:

$\mathrm{W}=\{\mathrm{w} 1, \mathrm{w} 2, \ldots, \mathrm{wn}\}$

Rating kinerja (X) dan nilai bobot (W) merupakan nilai utama yang merepresentasikan preferensi absolut dari pengambil keputusan. Masalah multi atribut decision making diakhiri dengan proses perankingan untuk mendapatkan alternatif terbaik diperoleh berdasarkan nilai keseluruhan preferensi yang diberikan (Yeh, 2002).

D. Simple Additive Weighting Method (SAW)

Metode simple addtive weighting sering juga dikenal dengan istilah penjumlahan terbobot. Konsep dasar metode simple additive weighting adalah mencari penjumlahan terbobot dari rating kinerja pada setiap alternatif pada semua atribut (Fishburn, 1976) (MacCrimmon, 1968). Metode simple additive weighting membutuhkan proses normalisasi matriks keputusan (X) ke suatu skala yang dapat diperbandingkan dengan semua rating alternatif yang ada. 


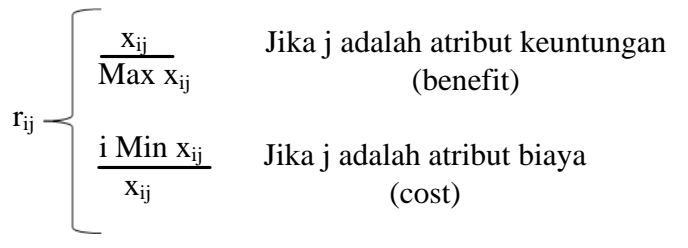

Dimana rij adalah rating kinerja ternormalisasi dari alternatif $\mathrm{Ai}$ pada atribut $\mathrm{Cj}$; $\mathrm{i}=1,2, \ldots, \mathrm{m}$ dan $\mathrm{j}=1,2, \ldots$,n.Nilai preferensi untuk setiap alternat if (Vi) diberikan sebagai :

$V_{1}=\sum_{j=1}^{n} w_{j} r_{i j}$

Nilai Vi yang lebih besar mengindikasikan bahwa alternatif Ai lebih terpilih.

E. Alur Penelitian

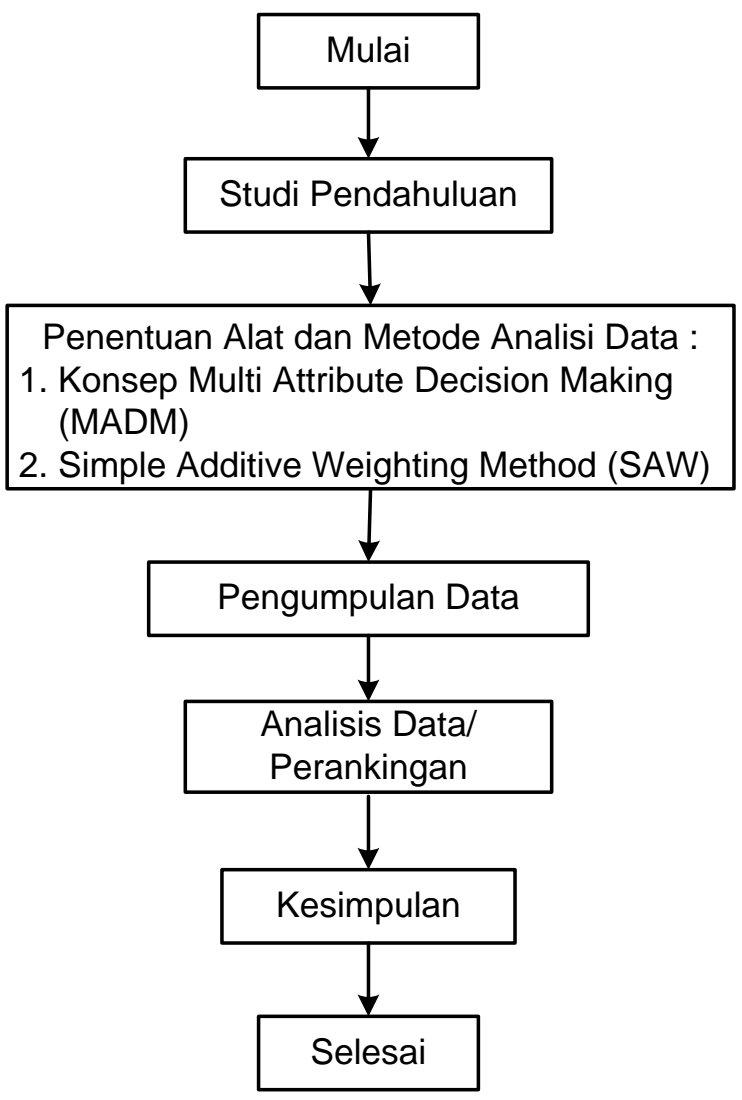

\section{Hasil Dan Pembahasan}

A. Kriteria Dan Bobot

Pemilihan prestasi Peminjam menggunakan model MADM dengan metode SAW (Simple Additive Weighting) diperlukan kriteria-kriteria dan bobot untuk melakukan perhitungan sehingga akan didapat alternatif terbaik. Berikut merupakan kriteria yang dibutuhkan untuk pengambilan keputusan. Kriteria dan bobot yang ditetapkan oleh komite koperasi dapat dilihat pada tabel 1 berikut

Tabel 1. Jenis Ktrieria Dan Bobot

\begin{tabular}{clcc}
\hline No & Jenis Kriteria & Kriteria & $\begin{array}{c}\text { Bobot } \\
(\%)\end{array}$ \\
\hline 1 & Jaminan & (C1) & $25 \%$ \\
2 & Pinjaman & (C2) & $20 \%$ \\
3 & Angsuran & (C3) & $15 \%$ \\
4 & Jangka Waktu & (C4) & $20 \%$ \\
5 & Penghasilan/Bulan & (C5) & $20 \%$ \\
\hline
\end{tabular}

Penjelasan dari tabel diatas adalah sebagai berikut pada tabel 2 : 
Tabel 2. Penjelasan Kriteria Dan Bobot

\begin{tabular}{cccccc}
\hline Skor & Jaminan & Pinjaman & Angsuran & Jangka Waktu & Penghasilan \\
\hline 4 & $>30 \mathrm{jt}$ & $>50 \mathrm{jt}$ & $>3 \mathrm{jt}$ & $30 \mathrm{bln}$ & $>3 \mathrm{jt}$ \\
3 & $>20 \mathrm{jt}$ & $>20 \mathrm{jt}$ & $>1,5 \mathrm{jt}$ & $14 \mathrm{bln}$ & $>2 \mathrm{jt}-<3 \mathrm{jt}$ \\
2 & $>10 \mathrm{jt}$ & $>5 \mathrm{jt}$ & $>500 \mathrm{ribu}$ & $12 \mathrm{bln}$ & $>1,5 \mathrm{jt}$ \\
1 & $>1 \mathrm{jt}$ & $>100 \mathrm{ribu}$ & $>100 \mathrm{ribu}$ & $3 \mathrm{bln}$ & $<1,5 \mathrm{jt}$ \\
\hline
\end{tabular}

B. Simulasi Metode

Jumlah sampel yang akan dinilai dalam simulasi ini adalah sebanyak 10 peminjam, sebagai contoh untuk penerapan model MADM (Multiple Attribute Decison Making) dengan metode SAW (Simple Additive Weighting) dalam penentuan pemberian kredit pinjaman. Nama nama anggota dimasukkan ke dalam tabel 3 dibawah ini.
Tabel 3. Data Anggota

\begin{tabular}{cll}
\hline $\begin{array}{c}\text { No } \\
\text { Urut }\end{array}$ & \multicolumn{1}{c}{ Nama } & \multicolumn{1}{c}{ Alamat } \\
\hline 1 & Edi Rahmawan & Hadimulyo Barat \\
2 & Subhan Adi & Hadimulyo Timur \\
3 & Ali Tikno & Metro Timur \\
4 & Bambang S & Metro Barat \\
5 & Peter Ali & Metro Pusat \\
6 & Keysa Ananda & Metro Pusat \\
7 & Raka Tresno A & Ganjar Agung \\
8 & Tirta Kurnia & Kauman \\
9 & Dian Paramitha & Karang Sari \\
10 & Resya Suzanna & Karang Wetan \\
\hline
\end{tabular}

a. Kecocokan dari setiap alternative pada setiap kreiteria dapat dilihat pada tabel 4 berikut :

Tabel 4. Tabel Kecocokan Dari Setiap Alternatif Pada Setiap Kriteria

\begin{tabular}{clccccc}
\hline \multirow{2}{*}{ Alternatif } & \multirow{2}{*}{ Nama Mahasiswa } & C1 & C2 & C3 & C4 & C5 \\
\hline$V_{l}$ & Edi Rahmawan & 4 & 3 & 2 & 2 & 2 \\
$V_{2}$ & Subhan Adi & 3 & 3 & 2 & 3 & 1 \\
$V_{3}$ & Ali Tikno & 3 & 2 & 2 & 2 & 2 \\
$V_{4}$ & Bambang Suseno & 2 & 3 & 1 & 3 & 2 \\
$V_{5}$ & Peter Ali Akbar & 2 & 2 & 2 & 3 & 3 \\
$V_{6}$ & Keysa Ananda & 2 & 2 & 3 & 2 & 1 \\
$V_{7}$ & Raka Tresno Aji & 3 & 3 & 2 & 2 & 1 \\
$V_{8}$ & Tirta Kurnia & 1 & 2 & 1 & 1 & 2 \\
$V_{9}$ & Dian Paramitha & 3 & 2 & 2 & 4 & 3 \\
$V_{10}$ & Resya Suzanna & 3 & 3 & 2 & 2 & 2 \\
\hline
\end{tabular}

b. Menentukan bobot pada setiap kriteria.

Untuk menentukan bobot penentuan pemberian kredit pinjaman dibentuk dalam table 5

Tabel 5. Bobot Penilaian

\begin{tabular}{cc}
\hline Kriteria & Bobot \\
\hline C1 & $25 \%$ \\
C2 & $20 \%$ \\
C3 & $15 \%$ \\
C4 & $20 \%$ \\
C5 & $20 \%$ \\
\hline
\end{tabular}

c. Menormalisasi matriks $\mathrm{X}$ menjadi matriks $\mathrm{R}$ berdasarkan persamaan (1).
Karena setiap nilai yang diberikan pada setiap alternatif di setiap kriteria merupakan nilai kecocokan (nilai terbesar adalah terbaik) maka semua kriteria yang diberikan diasumsikan sebagai kriteria keuntungan (benefit).

Berikut ini perhitungan normalisasi matriks X berdasarkan persamaan (1) sebagai berikut:

a. Jaminan:

$r 11 \frac{4}{4: 3: 3: 2: 2: 2: 3: 1: 3: 3}=1$ 


$$
\begin{aligned}
& r 21 \frac{3}{4: 3: 3: 2: 2: 2: 3: 1: 3: 3}=0,750 \\
& r 31 \frac{3}{4: 3: 3: 2: 2: 2: 3: 1: 3: 3}=0,750 \\
& r 41 \frac{2}{4: 3: 3: 2: 2: 2: 3: 1: 3: 3}=0,500 \\
& r 51 \frac{2}{4: 3: 3: 2: 2: 2: 3: 1: 3: 3}=0,500 \\
& r 61 \frac{2}{4: 3: 3: 2: 2: 2: 3: 1: 3: 3}=0,500 \\
& r 71 \frac{3}{4: 3: 3: 2: 2: 2: 3: 1: 3: 3}=0,750 \\
& r 81 \frac{1}{4: 3: 3: 2: 2: 2: 3: 1: 3: 3}=0,250 \\
& r 91 \frac{3}{4: 3: 3: 2: 2: 2: 3: 1: 3: 3}=0,750 \\
& r 101 \frac{3}{4: 3: 3: 2: 2: 2: 3: 1: 3: 3}=0,750
\end{aligned}
$$

b. Pinjaman :

$$
\begin{aligned}
& r 12 \frac{3}{3: 3: 2: 3: 2: 2: 3: 2: 2: 3}=1 \\
& r 22 \frac{3}{3: 3: 2: 3: 2: 2: 3: 2: 2: 3}=1 \\
& r 32 \frac{2}{3: 3: 2: 3: 2: 2: 3: 2: 2: 3}=0,667
\end{aligned}
$$$$
r 42 \frac{3}{3: 3: 2: 3: 2: 2: 3: 2: 2: 3}=1
$$$$
r 52 \frac{2}{3: 3: 2: 3: 2: 2: 3: 2: 2: 3}=0,667
$$$$
r 62 \frac{2}{3: 3: 2: 3: 2: 2: 3: 2: 2: 3}=0,667
$$$$
r 72 \frac{3}{3: 3: 2: 3: 2: 2: 3: 2: 2: 3}=1
$$$$
r 82 \frac{2}{3: 3: 2: 3: 2: 2: 3: 2: 2: 3}=0,667
$$$$
r 92 \frac{2}{3: 3: 2: 3: 2: 2: 3: 2: 2: 3}=0,667
$$

$$
r 102 \frac{3}{3: 3: 2: 3: 2: 2: 3: 2: 2: 3}=1
$$

c. Angsuran :

$r 13 \frac{2}{2: 2: 2: 1: 2: 3: 2: 1: 2: 2}=0,667$

$r 23 \frac{2}{2: 2: 2: 1: 2: 3: 2: 1: 2: 2}=0,667$

$r 33 \frac{2}{2: 2: 2: 1: 2: 3: 2: 1: 2: 2}=0,667$

$r 43 \frac{1}{2: 2: 2: 1: 2: 3: 2: 1: 2: 2}=0,333$

$r 53 \frac{2}{2: 2: 2: 1: 2: 3: 2: 1: 2: 2}=0,667$

$r 63 \frac{3}{2: 2: 2: 1: 2: 3: 2: 1: 2: 2}=1$

$r 73 \frac{2}{2: 2: 2: 1: 2: 3: 2: 1: 2: 2}=0,667$

$r 83 \frac{1}{2: 2: 2: 1: 2: 3: 2: 1: 2: 2}=0,333$

$r 93 \frac{2}{2: 2: 2: 1: 2: 3: 2: 1: 2: 2}=0,667$

$r 103 \frac{2}{2: 2: 2: 1: 2: 3: 2: 1: 2: 2}=0,667$

d. Jangka Waktu :

$r 14 \frac{2}{2: 3: 2: 3: 3: 2: 2: 1: 4: 2}=0,500$

$r 24 \frac{3}{2: 3: 2: 3: 3: 2: 2: 1: 4: 2}=0,750$

$r 34 \frac{2}{2: 3: 2: 3: 3: 2: 2: 1: 4: 2}=0,500$

$r 44 \frac{3}{2: 3: 2: 3: 3: 2: 2: 1: 4: 2}=0,750$

$r 54 \frac{3}{2: 3: 2: 3: 3: 2: 2: 1: 4: 2}=0,750$

$r 64 \frac{2}{2: 3: 2: 3: 3: 2: 2: 1: 4: 2}=0,500$ 
$r 74 \frac{2}{2: 3: 2: 3: 3: 2: 2: 1: 4: 2}=0,500$ $r 84 \frac{1}{2: 3: 2: 3: 3: 2: 2: 1: 4: 2}=0,250$ $r 94 \frac{4}{2: 3: 2: 3: 3: 2: 2: 1: 4: 2}=1$ $r 104 \frac{2}{2: 3: 2: 3: 3: 2: 2: 1: 4: 2}=0,500$

e. Penghasilan/Bln :

$r 15 \frac{2}{2: 1: 2: 2: 3: 1: 1: 2: 3: 2}=0,667$ $r 25 \frac{1}{2: 1: 2: 2: 3: 1: 1: 2: 3: 2}=0,333$ $r 35 \frac{2}{2: 1: 2: 2: 3: 1: 1: 2: 3: 2}=0,667$ $r 45 \frac{2}{2: 1: 2: 2: 3: 1: 1: 2: 3: 2}=0,667$ $r 55 \frac{3}{2: 1: 2: 2: 3: 1: 1: 2: 3: 2}=1$ $r 65 \frac{1}{2: 1: 2: 2: 3: 1: 1: 2: 3: 2}=0,333$ $r 75 \frac{1}{2: 1: 2: 2: 3: 1: 1: 2: 3: 2}=0,333$ $r 85 \frac{2}{2: 1: 2: 2: 3: 1: 1: 2: 3: 2}=0,667$ $r 95 \frac{3}{2: 1: 2: 2: 3: 1: 1: 2: 3: 2}=1$ $r 105 \frac{2}{2: 1: 2: 2: 3: 1: 1: 2: 3: 2}=0,667$

Matrix R :

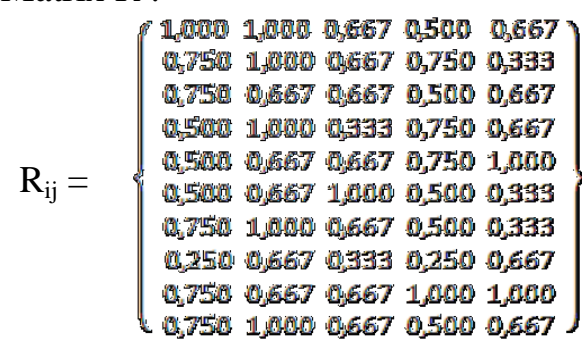

C. Melakukan Proses Perankingan

Dengan menggunakan persamaan (2): Berikut ini adalah perhitungan perankingan tersebut :

$$
\begin{aligned}
V_{1} & =(0.25 * 1.000)+(0.20 * 1.000)+(0.15 * 0.667) \\
+ & (0.20 * 0.500)+(0.20 * 0,667) \\
& =(0.250)+(0.200)+(0.100)+(0.150)+ \\
& (0,133) \\
& =0.783
\end{aligned}
$$

$$
\begin{aligned}
V_{2} & =(0.25 * 0.750)+(0.20 * 1.000)+(0.15 * 0.667) \\
+ & (0.20 * 0.750)+(0.20 * 0,333) \\
& =(0.188)+(0.200)+(0.100)+(0.150)+ \\
& (0,067) \\
& =0.704
\end{aligned}
$$

$$
\begin{aligned}
V_{3} & =(0.25 * 1.000)+(0.20 * 1.000)+(0.15 * 0.667) \\
+ & (0.20 * 0.500)+(0.20 * 0,667) \\
& =(0.188)+(0.200)+(0.100)+(0.100)+ \\
& (0,133) \\
& =0.654
\end{aligned}
$$

$$
\begin{aligned}
& V_{4}=(0.25 * 0.500)+(0.20 * 1.000)+(0.15 * 0.333) \\
& +(0.20 * 0.750)+(0.20 * 0,667) \\
& \quad=(0.125)+(0.200)+(0.050)+(0.150)+ \\
& \quad(0,133) \\
& \quad=0.658
\end{aligned}
$$

$$
\begin{aligned}
& V_{5}=(0.25 * 0.500)+(0.20 * 0.667)+(0.15 * 0.667) \\
& +(0.20 * 0.750)+(0.20 * 1,000) \\
& \quad=(0.125)+(0.133)+(0.100)+(0.150)+ \\
& \quad(0,200) \\
& \quad=0.708
\end{aligned}
$$

$$
\begin{aligned}
& V_{6}=(0.25 * 0.500)+(0.20 * 0.667)+(0.15 * 1.000) \\
& +(0.20 * 0.500)+(0.20 * 0,333) \\
& \quad=(0.125)+(0.133)+(0.150)+(0.100)+ \\
& \quad(0,067) \\
& \quad=0.575
\end{aligned}
$$

$$
\begin{aligned}
& V_{7}=(0.25 * 0.750)+(0.20 * 1.000)+(0.15 * 0.667) \\
& +(0.20 * 0.500)+(0.20 * 0,333) \\
& =(0.188)+(0.200)+(0.100)+(0.100)+ \\
& (0,067) \\
& =0.654 \\
& V_{8}=(0.25 * 0.250)+(0.20 * 0,667)+(0.15 * 0.333) \\
& +(0.20 * 0.250)+(0.20 * 0,667) \\
& =(0.063)+(0.133)+(0.050)+(0.050)+ \\
& (0,133) \\
& =0.429 \\
& V_{9}=(0.25 * 0.750)+(0.20 * 0.667)+(0.15 * 0.667) \\
& +(0.20 * 1.000)+(0.20 * 1,000)
\end{aligned}
$$




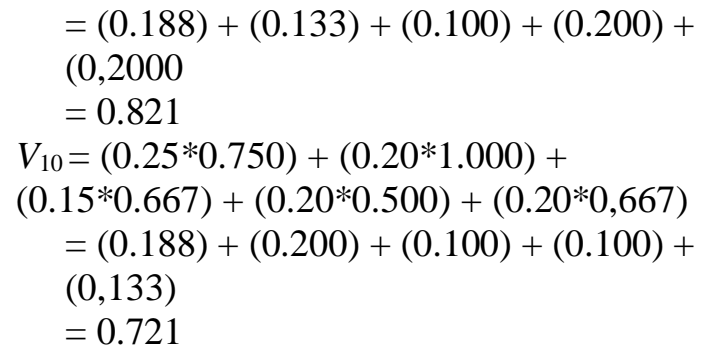

Berdasarkan perhitungan nilai tersebut, ada 5 calon peminjam yang berhak mendapat pinjaman kredit yang memiliki nilai hasil terbesar yaitu Dian Paramita, Edi Rahmawan, Resya Suzanna pada,Peter Ali Akbar dan Subhan Adi $V_{9}, V_{l}, V_{10}$ $V_{5}$ dan $V_{2}$ Untuk lebih jelasnya lihat table 6 berikut :

Tabel 6. Hasil Rangking

\begin{tabular}{clcccccc}
\hline \multirow{2}{*}{ Alternatif } & \multicolumn{1}{c}{ Nama } & $\mathrm{C} 1$ & $\mathrm{C} 2$ & $\mathrm{C} 3$ & $\mathrm{C} 4$ & $\mathrm{C} 5$ & Total \\
& & 0,188 & 0,133 & 0,100 & 0,200 & 0,200 & 0,821 \\
\hline $\mathrm{V}_{9}$ & Dian Paramitha & 0,250 & 0,200 & 0,100 & 0,100 & 0,133 & 0,783 \\
$\mathrm{~V}_{1}$ & Edi Rahmawan & 0,188 & 0,200 & 0,100 & 0,100 & 0,133 & 0,721 \\
$\mathrm{~V}_{10}$ & Resya Suzanna & 0,125 & 0,133 & 0,100 & 0,150 & 0,200 & 0,708 \\
$\mathrm{~V}_{5}$ & Peter Ali Akbar & 0.188 & 0,200 & 0,100 & 0,150 & 0,067 & 0,704 \\
$\mathrm{~V}_{2}$ & Subhan Adi & 0,125 & 0,200 & 0,050 & 0,150 & 0,133 & 0,658 \\
$\mathrm{~V}_{4}$ & Bambang Suseno & 0,188 & 0,200 & 0,100 & 0,100 & 0,067 & 0,654 \\
$\mathrm{~V}_{7}$ & Raka Tresno Aji & 0,188 & 0,133 & 0,100 & 0,100 & 0,133 & 0,654 \\
$\mathrm{~V}_{3}$ & Ali Tikno & 0,125 & 0,133 & 0,150 & 0,100 & 0,067 & 0,575 \\
$\mathrm{~V}_{6}$ & Keysa Ananda & 0,063 & 0,133 & 0,050 & 0,050 & 0,133 & 0,429 \\
$\mathrm{~V}_{8}$ & Tirta Kurnia & & & & & & \\
\hline
\end{tabular}

\section{Kesimpulan}

Berdasarkan analisa yang telah dilakukan, maka kesimpulan dalam penulisan ini adalah sebagai berikut:

1. Telah diimplementasikan sistem penunjang keputusan pemberian pinjaman anggota dengan menggunakan Simple Addictive Weighting $(S A W)$ di Koperasi Simpan Pinjam.

2. Sistem memberikan solusi terbaik didalam penentuan rekomendasi pemberian pinjaman kepada calon peminjam di koperasi.

3. Sistem hanya mampu mewakili 10 sample anggota sebagai rujukan dalam perhitungan pemberian pinjaman kredit.

4. Koperasi Simpan Pinjam Sarin Bumi Sedana hendaknya mengimplementasikan sistem penunjang keputusan ini untuk memudahkan penentuan rekomendasi pemberian pinjaman kredit.

\section{Daftar Pustaka}

Adriyendi, Using Simple Additive Weighting and Weighted Product in Food Choice, International Journal of Information Engineering and Electronic Business(IJIEEB) 7(6),2015, pp.8-14.

Fuad, M, H Christine, Nurlela, Sugiarto,dan Paulus
Y.E.F, 2006, Pengantar Bisnis, Erlangga, Jakarta.

Fishburn, P. C., A Problem multi of selection based - methods, making decision attribute. Blackwell Publishing, 1967.

Kusumadewi, S., Hartati, S., Harjoko, A., Wardoyo, R. Fuzzy Multi-Attribute Decision Making (Fuzzy MADM), Graha Ilmu, Yogyakarta-Indonesia, 2006.

Loebbecke, C., and Huyskens, C. Development of a model-based netsourcing decision support system using a five-stage methodology, European Journal of Operational Research 195, 2009, pp.653-661.

MacCrimmon, K. R., Making Decision and Survey Alternatives:atribut emultipleaning consolidated approach, 1968.

Nugroho, S., Wulandari, T.F., Penerapan Metode SAW dalam Penentuan Produk Kerajinan Unggulan Kabupaten Klaten, Jurnal SIMETRIS Vol 7 April, 2016, pp. 163168.

Rudolphi, Victoria. 2000. Multi Criteria Decision Analysis as A Framework for Integrated Land Use Management in Canadian National Parks"

Yeh, Chung-Hsing; Deng; Changan Y.-H 2000. Fuzzy Multi Criteria Analysis for Performance Evaluation of Bus Companies". International transaction in Operational Research, Blackwell Publshing. 